\title{
Determining the Safe Distance of the Waste Collection Site in Housing Areas of Thai Nguyen Province in Vietnam
}

\author{
Dao Dang Quang, Nguyen Tien Duc
}

\begin{abstract}
At the the waste collection site there are many different kinds of gases such as $\mathrm{CH}_{4}, \mathrm{CO}_{2}, \mathrm{NH}_{3}, \mathrm{CH}_{2} \mathrm{SH}, \mathrm{N}_{2} \ldots$ these emissions greatly affect the health of the surrounding people. Determining the minimum distance to place the waste collection site with housing is essential. This paper uses the Gaussian diffusion model to simulate and determine the concentration of emissions from the waste collection site by distance in specific climatic conditions for housing areas in Thai Nguyen province in Vietnam. Then determine a safe distance to arrange a place for waste collection site in the planning of residential areas in Thai Nguyen province in Vietnam.
\end{abstract}

Index Terms-Thai Nguyen; Housing areas; The waste collection site; Diffusion; Mecaptans; $\mathrm{NH}_{3}$.

\section{INTRODUCTION}

In Vietnam, the planning of waste collection site in housing areas has not been given adequate attention. The waste collection site emitting gases such as:: $\mathrm{CH}_{4}, \mathrm{CO}_{2}, \mathrm{NH}_{3}$, $\mathrm{CH}_{3} \mathrm{SH}, \quad \mathrm{N}_{2} \ldots$ (Table1) causing unpleasant smell and greatly affecting human health [1]. Researching the distance of the waste collection site placement so that waste concentrations do not affect people living in residential areas is an important issue to ensure the health of residents living in housing areas. There have been many studies offering solutions to arrange the waste collection site in housing planning [2, 3]. Previous studies have just stopped at the planning of the waste collection site based on criteria of the accessibility of traffic, consistent with the transport route to the centralized landfill sites but not concerned with determining a safe distance to place the waste collection site. Determining a safe distance to place a the waste collection site that has little impact on the surrounding population is a complex issue because the concentration of gases generated from the waste collection site depends on the diffusion process and climate conditions. In this paper, the Gaussian diffusion model is proposed to calculate the concentration of the waste collection site to determine the safe distance between houses and the waste collection site in the planning of housing areas of Thai Nguyen province in Viet Nam.

Dao Dang Quang, Facuty of civil and environment enrinering, Thai Nguyen University of Technology, Thai Nguyen, Vietnam, Mobile No $(+84)$ 0979867906.

Nguyen Tien Duc, Facuty of civil and environment enrinering, Thai Nguyen University of Technology, Thai Nguyen, Vietnam, Mobile No (+84) 982947666
Table 1. Gases in the waste collection site [1]

\begin{tabular}{|c|c|}
\hline Gases & \% (Dry volume) \\
\hline $\mathrm{CH}_{4}$ & $45-60$ \\
\hline $\mathrm{CO}_{2}$ & $40-60$ \\
\hline $\mathrm{N}_{2}$ & $2-5$ \\
\hline $\mathrm{O}_{2}$ & $0.1-1.0$ \\
\hline Mercaptans & $0-1.0$ \\
\hline $\mathrm{NH}_{3}$ & $0.1-1.0$ \\
\hline $\mathrm{H}_{2}$ & $0-0.2$ \\
\hline $\mathrm{CO}$ & $0-0.2$ \\
\hline Other gases & $0.01-0.6$ \\
\hline
\end{tabular}

\section{METHODOLOGY AND RESEARCH SUBJECTS}

This paper uses the Gaussian diffusion model [4, 5] to calculate the concentration of pollutant emissions declining by distance from the prevailing wind direction of winter and summer of Thai Nguyen province in Viet Nam. From that result, it is compared with [10] to determine the minimum distance of houses to the waste collection site.

\subsection{Gaussian diffusion model}

To calculate the decrease in gas concentration at the waste collection site, the coordinate system is calculated with the center located at the waste collection site, the $\mathrm{Oz}$ axis is set according to the height of the waste collection site, the OX axis is placed in the same direction with the wind blowing and the $\mathrm{OY}$ axis is set according to squared perpendicular to $\mathrm{OX}$ on the horizontal surface plane.

The equation describing the diffusion of emissions is as follows $[4,5,6,7]$ :

$$
\frac{\partial \epsilon}{\partial t}=\frac{\partial}{\partial y} D_{y} \frac{\partial c}{\partial y}+\frac{\partial}{\partial z} D_{z} \frac{\partial c}{\partial z}-v \frac{\partial c}{\partial x}-\lambda c
$$

General solution formula:

$c(x, y, z)=$

$\frac{Q}{4 \pi x_{\sqrt{D_{y} D_{z}}}} \exp \left(-\frac{v y^{2}}{4 x D_{y}}\right)\left[\begin{array}{l}\exp \left(-\frac{v(z-H)^{2}}{4 x D_{z}}\right) \\ +\exp \left(-\frac{v(z+H)^{2}}{4 x D_{z}}\right)\end{array}\right] \exp (-x)$

With the height of the waste source unchanged, we

have:

$$
\mathrm{C}(\mathrm{x}, \mathrm{y})=\frac{Q}{\pi v \sigma_{y} \sigma_{z}} \exp \left(-\frac{1}{2}\left(\frac{y^{2}}{\sigma_{y}^{2}}+\frac{H^{2}}{\sigma_{z}^{2}}\right)\right)
$$

Where: C - gas concentration $\left(\mathrm{gm}^{-3}\right) ; \mathrm{Q}$ - emission rate $\left(\mathrm{gs}^{-1}\right)$; v- wind speed $\left(\mathrm{ms}^{-1}\right) ; \sigma_{y^{-}}$diffusion coefficient for horizontal wind direction $(\mathrm{m}) ; \sigma_{z^{-}}$diffusion coefficient for vertical wind direction (m); H - Height of waste source (m); 


\subsection{Object and scope of the study}

The study area is characterized by the plain topography of hills that rise up to the north (Figure 1), the cold winter climate is strongly influenced by the southeast wind in the summer and the northeast wind and North in the winter. Houses of the study area are mostly 2-3-storey individual houses

THAI NGUYEN PROVINCE

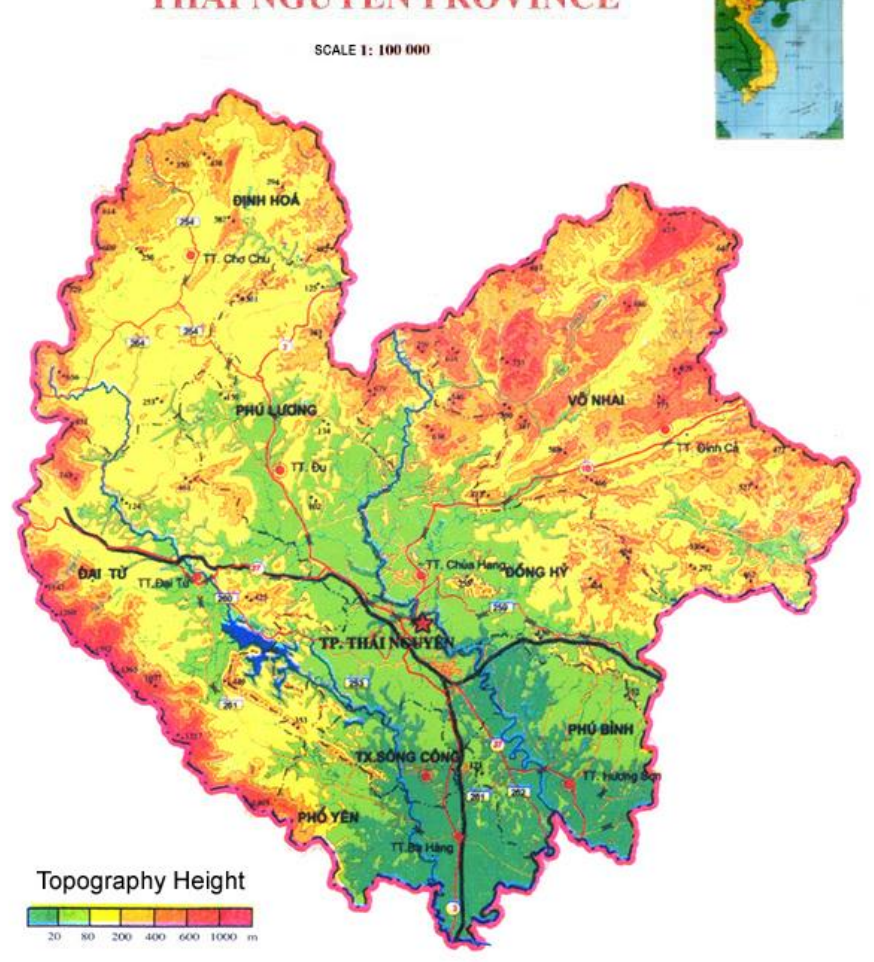

Figure 1. Topographic features of Thai Nguyen province in Vietnam [8]

According to the research results [1], the gases generated from the waste collection site have two gases that have the greatest impact on human health: $\mathrm{CH}_{3} \mathrm{SH}$ (Mecaptans) and NH3. Therefore, this study focuses on the calculation and simulation of diffusion of Mercaptans and $\mathrm{NH}_{3}$ (Table2).

Table 2. Emission rate, diffusion coefficients and permissible concentrations of Mercaptans and $\mathrm{NH}_{3}[9,10]$

\begin{tabular}{|c|c|c|}
\hline Gas & $\begin{array}{c}\text { Emission rate } \\
\left(\mathrm{mgm}^{-2} \mathrm{~s}^{-1}\right)\end{array}$ & $\begin{array}{c}\text { Permissible } \\
\text { concentrations } \\
\left(\mathrm{mgm}^{-3}\right)\end{array}$ \\
\hline Mercaptans & 58.93 & 0.05 \\
\hline $\mathrm{NH}_{3}$ & 308.95 & 0.2 \\
\hline
\end{tabular}

According to the current situation survey, the height of the waste collection sites varies from $1.5 \mathrm{~m}$ to $3 \mathrm{~m}$, the area of the waste collection sites ranges from $15 \mathrm{~m}^{2}$ to $30 \mathrm{~m}^{2}$. Therefore, in this study, height of waste source is $\mathrm{H}=3 \mathrm{~m}$, area of calculation $\mathrm{S}=30 \mathrm{~m}^{2}$ was selected for simulation calculation.

\section{RESEARCH RESULTS AND DISCUSSION}

In Thai Nguyen, the Meteorological Center over 3 years of continuous statistics show that the winter with the highest wind frequency is the Northeast and the North, with the highest wind frequency in the summer is the Southeast. In winter, the largest wind speed is $13.8 \mathrm{~ms}^{-1}$ and the smallest wind speed is $2.2 \mathrm{~ms}^{-1}$ in the northeast, the largest wind speed is $8.1 \mathrm{~ms}^{-1}$ and the smallest wind speed is $0.89 \mathrm{~ms}^{-1}$ in the north. In the summer, the largest wind speed is 7.2 $\mathrm{ms}^{-1}$ and the smallest wind speed is $1.8 \mathrm{~ms}^{-1}$ in the southeast. The remaining directions have low wind frequency, the largest wind speed is $6.7 \mathrm{~ms}^{-1}$ and the smallest is 0.44 $\mathrm{ms}^{-1}$ in all directions (Figure 2). Therefore, this study calculates a maximum wind speed of $13.8 \mathrm{~ms}^{-1}$ and a minimum wind speed of $0.89 \mathrm{~ms}^{-1}$ in winter and a maximum wind speed of $7.1 \mathrm{~ms}^{-1}$ and a minimum wind speed of 1.8 $\mathrm{ms}^{-1}$ in the summer. The remaining maximum wind speed is $6.7 \mathrm{~ms}^{-1}$ and the minimum wind speed is $0.44 \mathrm{~ms}^{-1}$ in the remaining seasons

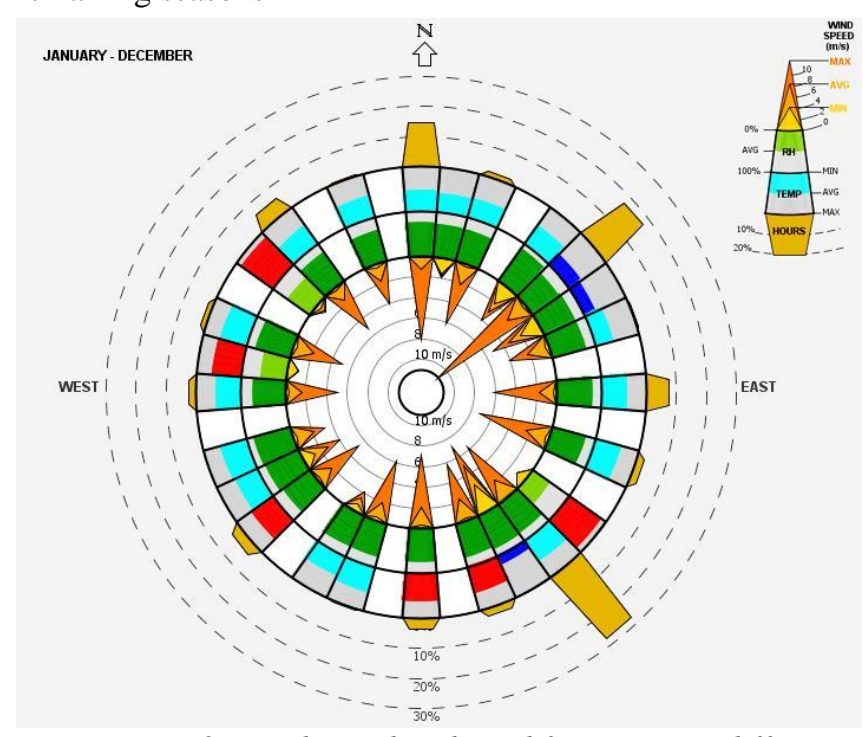

Figure 2. Wind speed and wind frequency in different directions in Thai Nguyen

Calculation results from the Gausian diffusion model for Mercaptans and NH3 in different wind directions and 
compared with the National Technical Regulation on Industrial Emission of Organic Substances are presented in
Tables 3 and 4.

Table 3. Mercaptans concentration by distance according to wind directions

\begin{tabular}{|c|c|c|c|c|c|c|c|c|c|c|c|}
\hline \multirow{4}{*}{ Winter } & \multirow[t]{2}{*}{ Wind $_{\max }$} & Dis (m) & 20 & 100 & 200 & 300 & 350 & 380 & 390 & 400 & $\left.\begin{array}{c}\mathrm{PC} \\
(m g m\end{array}\right)$ \\
\hline & & $\mathrm{C}(m g m)$ & 0.219 & 0.153 & 0.089 & 0.062 & 0.054 & 0.050 & 0.049 & 0.048 & \multirow{11}{*}{0.05} \\
\hline & \multirow{2}{*}{ Wind $_{\min }$} & Dis (m) & 20 & 100 & 200 & 300 & 400 & 410 & 420 & 430 & \\
\hline & & $\mathrm{C}\left(m g \mathrm{~m}^{-\pi}\right)$ & 0.948 & 0.202 & 0.103 & 0.069 & 0.052 & 0.050 & 0.049 & 0.048 & \\
\hline \multirow{4}{*}{ Summer } & \multirow{2}{*}{ Wind $_{\max }$} & Dis (m) & 20 & 100 & 200 & 300 & 350 & 400 & 410 & 420 & \\
\hline & & $\mathrm{C}\left(m g \mathrm{~m}^{-m}\right)$ & 0.464 & 0.178 & 0.096 & 0.066 & 0.057 & 0.050 & 0.049 & 0.048 & \\
\hline & \multirow{2}{*}{ Wind $_{\min }$} & Dis (m) & 20 & 100 & 200 & 300 & 400 & 410 & 420 & 430 & \\
\hline & & $\mathrm{C}(m g \mathrm{~m})$ & 0.845 & 0.201 & 0.102 & 0.068 & 0.051 & 0.050 & 0.049 & 0.048 & \\
\hline \multirow{4}{*}{$\begin{array}{l}\text { Remaining } \\
\text { seasons }\end{array}$} & \multirow{2}{*}{ Wind $_{\max }$} & Dis (m) & 20 & 100 & 200 & 250 & 350 & 400 & 410 & 420 & \\
\hline & & $\mathrm{C}\left(m g m^{-\pi}\right)$ & 0.491 & 0.180 & 0.097 & 0.078 & 0.057 & 0.050 & 0.049 & 0.048 & \\
\hline & \multirow{2}{*}{ Wind $_{\min }$} & Dis (m) & 20 & 100 & 200 & 300 & 400 & 410 & 420 & 430 & \\
\hline & & $\mathrm{C}(m g m)$ & 0.997 & 0.207 & 0.104 & 0.069 & 0.052 & 0.051 & 0.049 & 0.048 & \\
\hline
\end{tabular}

Table 4. $\mathrm{NH}_{3}$ concentration by distance according to wind directions $\left(\mathrm{mg}^{\mathrm{m}^{-3}}\right)$

\begin{tabular}{|c|c|c|c|c|c|c|c|c|c|c|c|}
\hline \multirow{4}{*}{ Winter } & \multirow{2}{*}{ Wind $_{\max }$} & Dis (m) & 20 & 100 & 200 & 400 & 500 & 510 & 520 & 520 & $\begin{array}{c}\mathrm{PC} \\
\left.\left(m^{\mathrm{m}}\right)^{-⿴}\right)\end{array}$ \\
\hline & & $\mathrm{C}(\mathrm{mgm})$ & 1.15 & 0.80 & 0.47 & 0.25 & 0.20 & 0.20 & 0.19 & 0.19 & \multirow{11}{*}{0.2} \\
\hline & \multirow{2}{*}{ Wind $_{\min }$} & Dis $(m)$ & 20 & 100 & 200 & 400 & 500 & 540 & 550 & 560 & \\
\hline & & $\mathrm{C}(\mathrm{mgm})$ & 4.94 & 1.07 & 0.54 & 0.27 & 0.21 & 0.20 & 0.19 & 0.19 & \\
\hline \multirow{4}{*}{ Summer } & \multirow{2}{*}{ Wind $_{\max }$} & Dis $(m)$ & 20 & 100 & 200 & 400 & 500 & 530 & 540 & 550 & \\
\hline & & $\mathrm{C}(\mathrm{mgm})$ & 2.43 & 0.93 & 0.50 & 0.26 & 0.21 & 0.20 & 0.19 & 0.19 & \\
\hline & \multirow{2}{*}{ Wind $_{\min }$} & Dis $(m)$ & 20 & 100 & 200 & 400 & 500 & 540 & 550 & 560 & \\
\hline & & $\mathrm{C}(\mathrm{mgm})$ & 4.48 & 1.05 & 0.53 & 0.27 & 0.21 & 0.20 & 0.19 & 0.19 & \\
\hline \multirow{4}{*}{$\begin{array}{l}\text { Remaining } \\
\text { seasons }\end{array}$} & \multirow{2}{*}{ Wind $_{\max }$} & Dis (m) & 20 & 100 & 200 & 400 & 500 & 530 & 540 & 550 & \\
\hline & & $\mathrm{C}(\mathrm{mg} m)$ & 2.57 & 0.94 & 0.50 & 0.26 & 0.21 & 0.20 & 0.19 & 0.19 & \\
\hline & \multirow{2}{*}{ Wind $_{\min }$} & Dis $(m)$ & 20 & 100 & 200 & 400 & 500 & 540 & 550 & 560 & \\
\hline & & $\mathrm{C}(\mathrm{mgm})$ & 5.22 & 1.08 & 0.54 & 0.27 & 0.21 & 0.20 & 0.19 & 0.19 & \\
\hline
\end{tabular}

From the calculation results shown in table 3 and table 4 , for Mercaptans we can see that the distance of waste source has a concentration greater than the permitted standard is $420 \mathrm{~m}$ and for $\mathrm{NH}_{3}$ the distance of the waste source has a concentration greater than the permitted standard is $550 \mathrm{~m}$. Therefore, when planning of the waste collection site in the housing areas of Thai Nguyen province to ensure a safe distance for the health of the residents, it must arrange the waste collection site at least $550 \mathrm{~m}$ away the housing.

\section{CONCLUSION}

The waste collection site of Thai Nguyen province in Vietnam produces a lot of gases which greatly affect the health of residents in the housing area. Including Mercaptans and $\mathrm{NH}_{3}$ are the gases that have the largest impact on health of people. The paper uses the Gaussian dispersion model to determine the gas concentration of the waste collection site by distance in specific climatic conditions for housing areas of Thai Nguyen province in Viet Nam. The model shows that the safe distance of waste dumping ground to housing in rural mountainous residential areas in Thai Nguyen province is $550 \mathrm{~m}$ in all seasons.

\section{REFERENCES}

[1] Health protection agency, Impact on health of emissions from landfill sites, Documents of the Health protection agency, 2011

[2] Tran Hieu Nhue, Ung Quoc Dung, Tran Thi Kim Thai, Solid waste management curriculum, Volume 1, Publisher Construction, 2001

[3] Tran Thi My Dieu, domestic solid waste management, Van Lang University Publishing, 2010
[4] Kathirgamanathan P, McKibbin R, McLachlan RI, "Source Term Estimation of Pollution from an Instantaneous Point Source". Res Lett Inf Math Sci 3:59-67, 2002

[5] Vaz AIF and Ferreira EC, "Air pollution control with semi-infinite programing”, XXVIII Congreso Nat. De Estadística e Investigatión Operativa, Cádiz, 2004

[6] Ekkehard Holzbecher, Environmental modeling, Springer, 2012

[7] Vu Khac Bay and partners, "Diffusion coefficient in Gauss model of the problem of spreading pollutants in the atmosphere", Journal of forestry science and technology, № 6-2016, pp 115-123

[8] Department of Natural Resources and Environment of Thai Nguyen Province, Administrative map of Thai Nguyen province, Thai Nguyen, 2019 [9] Mai Thi Thu Thao, Dinh Xuan Thang, Bui Ta Long, "Research of estimating emission factors of polution gas from landfills ( $\mathrm{CH} 4, \mathrm{H} 2 \mathrm{~S}, \mathrm{NH}$,

Methyl Mercaptan)", Journal of scientific and technological development, Volume 18, No M2-2016, 2016

[10] Ministry of Natural Resources and Environment, National Technical Regulation on Hazardous Substances in Ambient Air, Hanoi, 2009 